\title{
Post-operative Paraplegia with Spinal Myoclonus Possibly Caused by Epidural Anaesthesia: Case Report
}

\author{
K. Hachisuka, MD, H. Ogata, MD, K. Kohshi, MD \\ Department of Rehabilitation Medicine, University of Occupational and Environmental \\ Health, 1-1 Iseigaoka, Yahatanishi-ku, Kitakyushu-shi, Fukuoka-ken, 807 Fapan.
}

\begin{abstract}
Summary
We report a patient who developed paraplegia following percutaneous nephrolithotresis of the left kidney under epidural anaesthesia. The cause of the paraplegia was unknown, but occlusion of the anterior spinal artery or central arteries and arachnoiditis, possibly due to the epidural anaesthesia, may have taken part in the onset and progression of the paralysis. The patient had spinal myoclonus corresponding to the spinal levels where myelomalacia was found by magnetic resonance $(M R)$ imaging.
\end{abstract}

Key words: Paraplegia; Epidural anaesthesia; Percutaneous nephrolithotresis Myoclonus.

Epidural anaesthesia has become popular in recent years, and has proved to be safe. Complications are very rare, but one serious well recognised sequela is paraplegia with an incidence of 1 per 11000 procedures (Usubiaga, 1975), and 2 per 10000 lumbar epidural blocks (Dawkins, 1969). Usubiaga (1975) carried out an extensive review of the neurological complications following epidural anaesthesia. Adriani (1986) described the three most important causes of paraplegia after epidural anaesthesia: (1) arachnoiditis; (2) trauma to the spinal cord; (3) ischaemia from cord compresion or vascular disturbances.

In this paper we present a case report of a patient who developed paraplegia following percutaneous nephrolithotresis of the left kidney under epidural anaesthesia and who had spinal myoclonus.

\section{Case report}

A 53-year-old female had been suffering from a stone in the left renal pelvis for 5 years till she was admitted to hospital for a percutaneous nephrolithotresis in September 1987. Clinical X-ray examinations revealed no abnormality apart from a stone in her left renal pelvis.

In the operating room on 9 September, in the left lateral and flexed position, an epidural catheter was introduced by the paramedian approach in the $T_{11-12}$ interspace with a loss of resistance technique, without any difficulties. An $8 \mathrm{ml}$ dose of $2 \%$ mepivacaine was injected, subsequent to a $2 \mathrm{ml}$ test dose. This produced an anaesthetic level below $\mathrm{T}_{5}$, with no 
abnormal symptoms or signs. During the procedure she was additionally given $4 \mathrm{ml}$ doses of $2 \%$ mepivacaine 1 and 2 hours after the initial administration. Immediately after the first additional administration she complained of a burning pain in her lower back radiating down to her legs, lasting for several minutes. When the 2-hour operation was completed, she complained of pain in a girdle distribution, and a $2 \mathrm{mg}$ dose of morphine hydrochloride mixed with $5 \mathrm{ml}$ of saline solution with 1:200 000 epinephrine was given through the epidural catheter. After her return to the ward from the operating room, she complained of moderate muscle weakness in her hips and knees and sensory deficits in girdle distribution. The patients' blood pressure before the operation was $118-102 / 80-58 \mathrm{~mm} \mathrm{Hg}$; during the operation 146-110/86-70; subsequent to the epidural anaesthesia 146-110/86-70; and after the operation 120-100/74-60. Thus there was no significant hypotension.

As she had muscle weakness, sensory deficits and urinary retention, she had a whole body CT examination on 10 September. This examination did not disclose any evidence of haemorrhage, haematoma or disc protrusion in the vertebral canal. She was seen by a consultant neurologist on 12 September. The neurological findings consisted of bilateral moderate muscle weakness of the iliopsoas and quadriceps femoris, slight muscle weakness of the bilateral tibialis anterior and gastrocnemius, sensory deficits in the girdle distribution

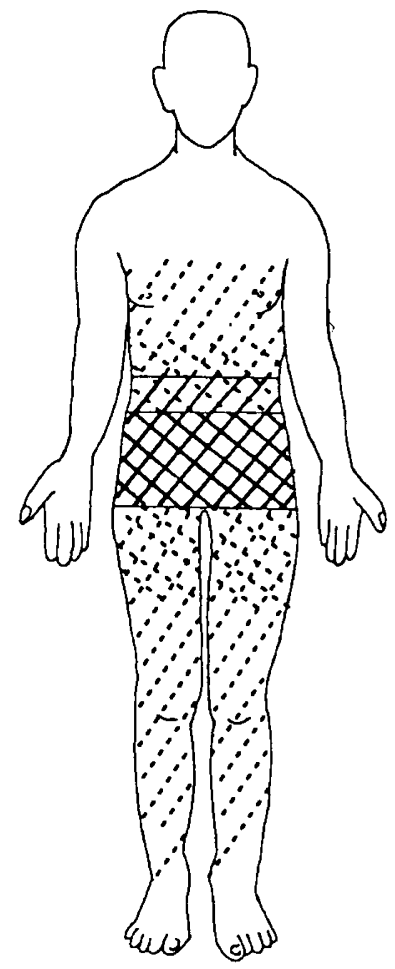

Figure 1 Sensory deficits on 12 September 1987. Analgesia: $\mathscr{Z}$; Hypalgesia: Hypesthesia: $\mathrm{N}$. Vibration and position senses: good at the toes.

(Fig. 1) with position and vibration senses spared at the toes, diminished knee reflexes, normal ankle reflexes and plantar reflexes. Four millilitres of transparent yellow cerebrospinal fluid (CSF) was obtained by a lumber puncture with an initial pressure of $130 \mathrm{~mm} \mathrm{H}_{2} \mathrm{O}$, containing $16 / 3$ lymphocytes and $1260 \mathrm{mg} / \mathrm{dl}$ protein, with a negative Queckenstedt's test. A myelogram on 17 September showed complete arrest of the contrast medium at the L1 level, suspicious of arachnoiditis, and no evidence of an A-V malformation. MR images performed on 18 September demonstrated swelling of the thoracic spinal cord.

Because of the continuing paralysis, the patient was transferred to the Department of 
Neurology in the University Hospital for further evaluation and treatment on 22 September, and was referred to the rehabilitation clinic on 30 September. Though the deep tendon reflexes were slightly exaggerated in the legs with positive plantar responses when she was seen at the first examination in our clinic, muscle power in the lower extremities, all modalities of sensations below T9 and deep tendon reflexes in the legs gradually disappeared with time, resulting in complete flaccid paraplegia by November.

After complaining of intermittent abdominal muscle spasms and paraesthesiae at the $\mathrm{T} 4$ 8 levels, on 10 May 1988 she was transferred to our Department of Rehabilitation Medicine for intensive rehabilitation. There were three reasons for diagnosing the muscle spasms as 'spinal myoclonus': an electromyogram (EMG) recorded with an 8-channel portable electroencephalography machine showed that the muscular contractions were localised to the abdominal muscles; a simultaneously recorded electroencephalogram did not show any cerebral spikes; and MR images performed in October disclosed myelomalacia in the centre of the spinal cord between T6 and T9 (Fig. 2). To relieve the spinal myoclonus and paraesthesiae, she had clonazepam $1.0 \mathrm{mg}$ per day, which abolished the spinal myoclonus and the paraesthesiae partially decreased within a few days.

In June 1988, needle EMGs revealed denervation potentials in posterior myotomes at the levels of T10, L2, and L5, and no voluntary muscle contractions were detected in her lower extremities. The patient was confined to a wheelchair, and performed self-catheterisations for persistent urinary retention. She was able to perform her daily activities without any assistance after intensive rehabilitation training, and was discharged on 10 March 1989.

\section{Discussion}

The cause of the paraplegia is still unsolved, but we presume that the anaesthetist did not make any technical mistakes and that an anaesthetic drug may have given rise to the arachnoiditis and vascular disturbances of the spinal cord.

It was evident that the procedure of the epidural catheter placement by the anaesthetist did not cause any trauma to the spinal cord because neither blood nor CSF flowed from the needle when the epidural puncture was done, and because neither haematoma nor haemorrhage in and around the spinal cord was revealed by $\mathrm{CT}$ and $\mathrm{MR}$ imaging.

The following findings, however, suggest that vascular mechanism may have played an important role in the development of the spinal cord injury (Silver, 1974).

1. There was burning pain radiating to her lower extremities at the onset of the paraplegia.

2. She had dissociation of sensory deficits and sacral sparing during the initial several weeks.

3. There was myelomalacia in the centre of the spinal cord at the level of the sixth to the ninth thoracic vertebral bodies as seen in the MR images.

Lazorthes 1975 described occlusion of a single central (sulcocommissural) artery producing central softening limited to one segment. As a few small areas of myelomalacia were found in the spinal cord in this patient, it is thought that the central arteries of the thoracic spinal cord may have been occluded, possibly by angiospasm from epidural injection of the anaesthetic drug.

In addition to the vascular disturbances of the spinal cord, arachnoiditis following chemical damage to the spinal cord and nerve roots, possibly induced by the anaesthetic drug or its preservative, may have caused the deterioration of the paralysis (Braham, 1958; Kliemann, 1975; Reisner, 1980; Sghirlanzoni, 1989). 
A
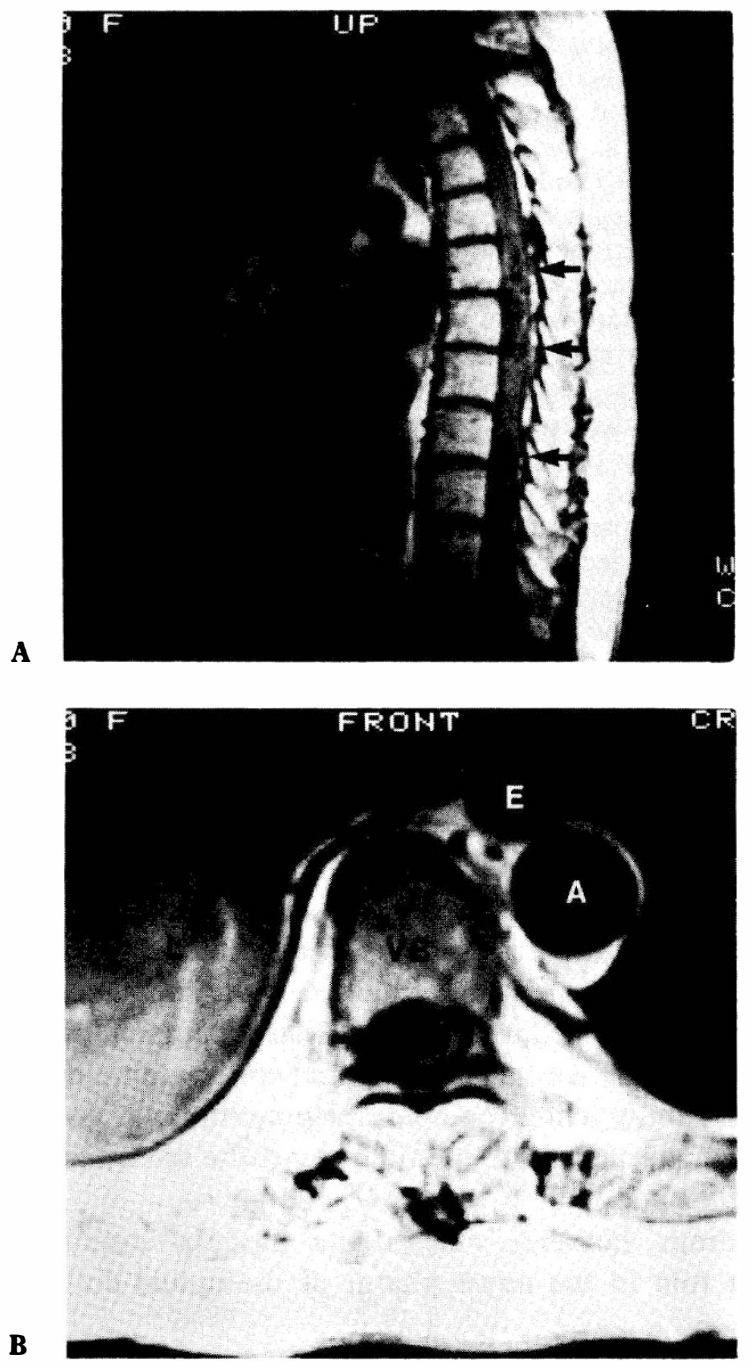

Figure 2 Tl weighted MR images in October 1988. (A) A longitudinal section of the thoracic spinal cord. Three low intensity areas (arrows) were shown in the spinal cord at the levels of sixth, seventh and ninth vertebral bodies. White bar $=5 \mathrm{~cm}$; TR $1100 \mathrm{msec}$, TE $150 \mathrm{msec}$. (B) A transverse section of the thoracic spinal cord at the level of the ninth thoracic vertebral body. An oval low intensity area (arrow) with sharp margin was seen in the centre of the spinal cord. A: aorta thoracica, E: oesophagus, L: liver, VB: ninth thoracic vertebral body. White bar $=5 \mathrm{~cm}$; TR $1200 \mathrm{msec}$, TE 150 msec.

Not only post-ischaemic spinal oedema but also a direct chemical effect on the spinal cord followed by arachnoiditis are suggested, because a myelogram showed changes suspicious of arachnoiditis, EMGs exhibited denervation potentials in the lumber myotomes, and there was slow progressive deterioration of the paralysis.

Arachnoiditis and cord changes are a direct expression of a chemical meningomyelopathy resulting from inadvertent injection of anaesthetic drugs into the subarachnoid space (Braham, 1958). Our patient did not display any symptoms or signs from the subarachnoid injection. Sghirlanzoni 1989 considered that the 
anaesthetic solution might reach the subarachnoid space not only through inadvertent and direct introduction in small quantities during the anaesthetic procedure but also through direct diffusion across the dura or centripetal spread through the dural root cuffs.

Though the epidural injection of morphine hydrochloride and epinephrine (Urquhart-Hay, 1969), and the percutaneous nephrolithotresis may also have given rise to or have affected the neurological complications, it is uncertain whether they had a direct relation to the onset of the paralysis.

The patient complained of spinal myoclonus approximately 5 months after the paralysis occurred. Spinal myoclonus is characterised by involuntary, semirhythmic contractions of the skeletal muscle groups innervated by a limited spinal cord region (Aigner, 1960; Swanson, 1962; Shivapour, 1980). The reported causes of spinal myoclonus reviewed by Jankovic 1986 included spinal tumour, vacuolar degeneration of anterior horn cells, spinal root lesion, myelitis, spinal anaesthesia, penicillin, arteriovenous malformation, herpes zoster and other infections, meningomyelocele, injury to the spine or the brachial plexus, spondylosis, and various neurodegenerative processes. Fox (1979) reported spinal myoclonus following lumbar anaesthesia, but we have not come across any cases of spinal myoclonus following epidural anaesthesia in the literature.

Although the underlying biochemical mechanisms unknown, spinal myoclonus is remarkably sensitive to medical therapy with clonazepam, valproate, carbamazepine, L-5-hydroxy-tryptophan, and tetrabenazipine (Jankovic, 1986). Clonazepam treatment for our patient also produced excellent control of the spinal myoclonus.

Shivapour 1980 described myoclonic contractions of the abdominal wall muscles and the lower extremities corresponding to the level of the spinal cord where a focal morphologic change consisting of vacuolar degeneration and chromatolysis was found. Our patient had myelomalacia in the thoracic spinal cord in the MR images. Therefore the pathological changes in and around the anterior horns of the spinal cord may induce an increased excitability of partially denervated anterior horn cells or residual non-injuried anterior horn cells.

\section{References}

ADRIAN J, NARAgi M 1986 Paraplegia associated with epidural anaesthesia. Southern Medical fournal 79:1350-1355.

Aigner BR, Mulder DW 1960 Myoclonus. Archives of Neurology 2:600-615.

BRAHAM J, SAIA A 1958 Neurological complications of epidural anaesthesia. British Medical foumal 2:657-658.

DAWKINS CJM 1969 Analysis of the complication of extradural and caudal block. Anaesthesia 24:554 563.

Fox EJ, Villanueva R, SchutTa HS 1979 Myoclonus following spinal anaesthesia. Neurology 29:379_ 380.

Jankovic J, PARDo R 1986 Segmental myoclonus. Archives of Neurology 43:1025-1031.

KLIEMANN FDD 1975 Paraplegia and intracranial hypertension following epidural anaesthesia. Arquivos de Neuropsiquiatria 33:217-229.

LAZORTHES G 1975 Pathology, classification and clinical aspects of vascular diseases of the spinal cord: Handbook of clinical neurology. Vol 12, New York, American Elsevier Publishing Co, pp 492-506.

ReISNer LS, Hochman BN, Plumer MH 1980 Persistent neurologic deficit and adhesive arachnoiditis following intrathecal 2-chloroprocaine injection. Anaesthesia and Analgesia 59:452-454.

Sghirlanzoni A, Marazzi R, Pareyson D, Olivieri A, Bracchi M 1989 Epidural anaesthesia and spinal arachnoiditis. Anaesthesia 44:317-321. 


\section{PARAPLEGIA}

ShivaPOUR E, TEASDALl RD 1980 Spinal myoclonus with vaculoar degeneration of anterior horn cells. Achives of Neurology 37:451-452.

SILVER JR, BUXTON PH 1974 Spinal stroke. Brain 97:539-550.

SKouEN JS, WAINAPEL SF, WILlOCK MM 1985 Paraplegia following epidural anaesthesia. Acta Neurologica Scandinavica 72:437-443.

SwANSON PD, LUTRRELl CN, MAGLADERY JW 1962 Myoclonus: a report of 67 cases and review of the literature. Medicine 41:339-356.

URQUHART-HAY D 1969 Paraplegia following epidural analgesia. Anaesthesia 24:461-470.

UsUBIAGA JE 1975 Neurological complications following epidural anaesthesia. International Anesthesiological Clinic 13:1-153. 